\title{
Pulsed-Dose Rate Brachytherapy
}

National Cancer Institute

\section{Source}

National Cancer Institute. Pulsed-Dose Rate Brachytherapy. NCI Thesaurus. Code

C116542.

A method of delivering internal beam radiotherapy that involves delivering short bursts of radiation over a specified period of time. 